\title{
Non-Contact Specular Microscopy
}

National Cancer Institute

\section{Source}

National Cancer Institute. Non-Contact Specular Microscopy. NCI Thesaurus. Code C120697.

A type of specular microscopy in which the specular microscope does not make contact with the cornea of the eye. 